\title{
Biomass Mass Production and Partitioning in Seedling of Harerghe Coffee Genotypes Under Deficit Irrigation at Jimma, Southwest Ethiopia
}

\author{
Minda Tadesse \\ Department of Irrigation and Water Harvesting Research, Jimma Agricultural Research Centre, Jimma, Ethiopia \\ Email address: \\ mindat9@gmail.com

\section{To cite this article:} \\ Minda Tadesse. Biomass Mass Production and Partitioning in Seedling of Harerghe Coffee Genotypes Under Deficit Irrigation at Jimma, \\ Southwest Ethiopia. American Journal of Life Sciences. Vol. 9, No. 4, 2021, pp. 67-72. doi: 10.11648/j.ajls.20210904.12
}

Received: May 9, 2021; Accepted: July 9, 2021; Published: July 15, 2021

\begin{abstract}
In Ethiopia, the coffee production is highly constrained by drought. To overcome such problem, knowing the behavior of coffee genotype's biomass accumulation pattern to different parts under contrasting moisture stress is important in selection of drought tolerant genotypes. Therefore, the objectives of the present study were to evaluate and characterize the biomass partitioning patterns of Harerghe coffee genotypes as influenced by deficit irrigation in rain shelter at Jimma agricultural research center. An experiment was conducted in completely randomized block design with three replications, where treatments consisted of three deficit level (40, 80 and 120\% of ETc) and six genotypes (H-674/98, H-739/98, H-823/98, H-981/98, H-929/98 and H-857/98). The result showed that the coffee dry-biomass partitioning patterns were significantly varied due deficit irrigation and genotypes as well as their interactions. Overall, the biomass assimilation and allocation were higher for roots $(37 \%)$ under $40 \%$ ETc and finally dropped to $23 \%$ under well watered seedlings, the investment made in root at the expense of shoot in drought conditions, enables the plants to extract more water from dipper soil layers, if water is limited in upper soil layers Conversely, the dry matters portioned to leaf were greater (48\%) under well watered seedlings and finally dropped to $26 \%$ under water stressed conditions. The accumulation of more dry-mater to leaf in well irrigated environment enables the plants to enhance photosynthetic capacity and thereby improve plant growth. Lastly, the study of dry biomass partitioning patterns in different parts of coffee plant is crucial important to decide appropriate watering amount and identifying drought tolerant genotypes for future breeding program under variable climatic conditions.
\end{abstract}

Keywords: Deficit Irrigation, Biomass Production, Biomass Partitioning, Coffee Seedling, Harerghe Coffee Genotypes

\section{Introduction}

Coffee is one of the most important agricultural commodities, ranking second in international trade after crude oil. The total global production of green coffee is above 134.16 million bags (60 $\mathrm{kg}$ capacity) with a retail sales value in excess of $\$ 22.7$ billion during $2010-11$ in the world market. The economics of many coffee growing countries depends heavily on the earnings from this crop. More than 100 million people in the coffee growing areas worldwide derive their income directly or indirectly from the produce of this crop [1].

Similarly, Coffee (Coffeaarabica L.) plays a significant role in the national economy of Ethiopia, contributing over $60 \%$ of the foreign exchange earnings and $30 \%$ of the government's direct revenue. Furthermore, the livelihood of $25 \%$ of the population depends on the coffee industry. However, the average national yield of the crop is very low primarily because of lack of improved varieties for different areas, diseases and pests and seasonal water deficits [2].

Coffee Arabica was belongs to shade loving plant species, and therefore most traditionally cultivation is taking place under shaded conditions $[1,2]$. The coffee production under shade is suffered of radiation and nutrient competition, finally may leads to restrict production. Thus, to increase yield and income intensively managed full-sun coffee production systems combined with appropriate irrigation were introduced in different parts of the world [4-7]. Yet, there have been disappointing experiences with full-sun cultivation and the consensus seems to be that under full-sun 
exposure adequate resources of nutrients (e.g. N) and water need to be provided to avoid problems such as reinforced biennial bearing and branch die back $[8,9]$ and reduced economic lifespan of the trees [10]. However, the optimal combinations of radiation and nutrient supply are hard to define.

Likewise, serious water deficits and deteriorating environmental quality are threatening agricultural sustainability in large parts of Asia and Africa. Overall, drought and unfavorable temperatures are the major climatic limitations for coffee production. Coffee is therefore a highly environmentally-dependent crop and an increase of a few degrees of average temperature and/or short periods of drought in coffee-growing regions can substantially decrease yields of quality coffees. Taking into account the global warming phenomena, severe reductions of adequate coffees growing areas are to be expected [11].

A complementary approach to improve plant performance for drought-prone regions involves the identification and selection of traits that contribute to drought tolerance. A partial list of potentially important traits might include waterextraction efficiency, water-use efficiency, hydraulic conductance, osmotic and elastic adjustments, and modulation of leaf area. Most of these traits are complex and their control and molecular basis is not well understood [12].

The leaf areas of coffee plant are indirectly affected by translocation of dry matter to organ parts (root, trunk, leaves and branches). Based on the functional equilibrium theory $[13,14]$, one would expect allocation to the shoot, particularly to leaves, to increase with larger nitrogen supply, and sufficient water supply as well as larger degree of shading. The fraction of total plant dry weight allocated to leaves, leaf weight ratio is a determinant of relative growth rate of trees in early stages [15]. The allocations of biomass to leaves versus other plant part are determined by leaf weight ratio. Higher leaf weight ratio means faster expansion of leaf area and light capture than in case of low leaf weight ratio. Therefore, leaf area ratio tells us the relative investment in leaves relatively. If the environment is conducive the invest ment to leaves and other part is become balanced, which maintain supply and preparation of carbons.

Dry matter production in coffee or other crops depends upon the leaf area index, the rate of photosynthetic rate, and the strength of the metabolic sinks in attracting assimilates [16]. If crops are to perform optimally, they must have regulatory mechanisms to ensure that photosynthetic and nitrogen assimilates are allocated to various parts of plant in ratios that provide well balanced whole plant functions. For example, during the vegetative growth stage, assimilates should be distributed to leaf production and production of new roots in ratios that provide a balance between the capacity for photosynthesis and the capacity for acquisition of mineral nutrients and water [17].

Different researchers investigated that the tree species changes in root: shoot ratio or the temporary build up of reserves in the stem is accompanied by change in nutrient, water availability and carbon metabolism, which affects dry matter partitioning [18-20]. According to some finding the net result of growth responses to decreased soil moisture availability is not only a decrease in plant growth rate, but a shift in the distribution of dry matter in favor of root biomass $[20,21]$. The allocation of dry matter among roots and shoots in seedlings developed different, because in each condition, the amount of water available to the seedling is varied. Seedlings indicate distinct variation in morphology and proportions of distribution and allocation of dry matter in the structures and root that are formed [22]. In Ethiopia, there is limited information about soil moisture deficit on dry matter allocation into varies plant parts of the coffee crop. Therefore, the objective of present study was to examine and characterize the effect of different soil moisture deficit levels on dry matter allocation patterns across different parts coffee seedlings.

\section{Materials and Methods}

The experiment was carried out for about five months during 2020 in a green house at Jima Agricultural Research Center (JARC) of the Ethiopian Agricultural Research institution (EIAR), Ethiopia. The research center is located at $7^{\circ} 40^{\prime} \mathrm{N}$ latitude, $36^{\circ} 47^{\prime} \mathrm{E}$ longitude, and at an altitude of $1753 \mathrm{~m}$ above sea level. The center receives an average annual rainfall of about $1540 \mathrm{~mm}$ with monthly mean maximum and minimum temperatures of 25.9 and $11.3^{\circ} \mathrm{C}$, respectively, and an average relative humidity of 67.2.

\subsection{Experimental Design}

The experiment was conducted in a completely randomized design in a factorial combination with three replications, where the treatments consisted of six Harerghe genotypes (H-674/98, H-739/98, H-823/98, H-981/98, H929/98 and H-857/98) and three irrigation levels (40, 80 and $120 \%$ ETc levels).

Each genotypes were combined with three irrigation amounts (6 genotypes $\mathrm{X} 3$ irrigation treatments), then combined treatments have been randomly allocated to experimental plots. Each experimental block contained 18 plots, 6 irrigated with $40 \%$ ETc, 6 irrigated with $80 \%$ ETc and 6 irrigated with $120 \%$ ETc, 8 plants per plot and totally 432 plants were evaluated in this experiment. All irrigation treatments were scheduled at four days interval based on field capacity determination and daily evaporation, accordingly individual varieties subjected to three irrigation amounts namely, 40\%, 80\% and 120\% ETc.

\subsection{Planting Material}

Pure seeds of 6 Harerghe coffee genotypes were prepared from promising and released Harerghe coffee from verification plots, and they were sown on nursery, managed according to recommended nursery mgt standards, vigor and healthy seedling of one year had transplanted to the pots of 5 liter volume in green house. One seedling were planted in each pot and watered to field capacity to facilitate well 
establishments.

\subsection{Parameter Measurements}

A destructive sampling method was used for determination of total dry matter production and its partitioning among plant parts. The two representative plants selected from each plot were harvested, then separated in to leaves, stem (including branches) and roots, and oven-dried at $70^{\circ} \mathrm{C}$ to a constant weight to determine total dry matter yield and its partitioning among leaves, stem and roots. The roots were immersed and washed in clean water to remove adhering soil. The dry-biomass partitioning to each plant body (leaf, stem, and root) were determined using equation 1 :

$$
P P(\%)=\frac{P P D W}{T D Y} * 100
$$

Where, $\mathrm{PP}=$ percent of dry biomass partitioned to leaf, stem or root separately, PPDW=plant part dry weight (leaf, stem and root), TDY=total dry matter yield $(\mathrm{TDY}=\mathrm{SDW}+\mathrm{LDW}+\mathrm{RDW}), \quad \mathrm{SDW}=$ stem dry weight, $\mathrm{LDW}=$ leaf dry weight, RDW=leaf dry weight.

\subsection{Field Capacity and Daily Evaporation Determination}

Sun-dried nursery soil was filled in pots, each with five liter capacity. The pots were weighed and watered to drip point, covered with a polyethylene sheet to prevent evaporation and allow free drainage for 24 hours. Then, the pots were reweighed to determine the field capacity (FC) of the soil and daily evaporation losses. The moisture content on dry weight basis was determined by gravimetric method (drying soil samples in an oven at $105^{\circ} \mathrm{C}$ to a constant weight) using 150-200g wet soil samples taken from wetted pots just after $24 \mathrm{hrs}$ and the loss of water on daily base were estimated on $\mathrm{v} / \mathrm{v}$ of percent. The pots were weighted daily for five consecutive days and the amount of moisture lost as evaporation (ETc) was calculated as the difference between initial pot weight and final pot weight. Then obtained weight (g/day/pot) was converted to water (liter/days/pot/). To make sure the calculation, soil sample was taken daily for five consecutive days and moisture loss due to evaporation were calculated. Based on these two methods the amount of irrigation water needed per day was determined and based up on daily evaporation loss, the irrigation scheduling was set to each four days.

\subsection{Statistical Analysis}

Data were analyzed in R-software with agricolae package $[23,24]$, using the general linear model procedure for factorial completely randomized block design. Significant differences between treatment means were separated using the Fisher's LSD-procedure at $\mathrm{p}<0.05$.

\section{Result and Discussion}

\subsection{Dry Biomass Partitioning}

Our result showed that, the percent of dry biomass distribution to leaves, stems and roots were quite different with fluctuating soil moistures. Therefore, the accumulation distribution of the dry biomass to the leaves, stems and roots were highly significantly $(\mathrm{P}<0.0001)$ affected due to variety, irrigations and interactions. Accordingly, the greater and lower dry biomass accumulation had allocated to roots and leaves respectively in $40 \%$ ETc level. In contrast, dry biomass partitioning was not significantly varied for leaves and roots in both $80 \%$ and $120 \%$ ETc levels. Plants treated under $40 \% \mathrm{ETc}$ had developed mechanisms of adjustments to drought in maintaining lower leaf dry matter and greater roots dry matter that enable them to save existing water and extract additional water from bottom of pots. The finding of Lahai and Ekanayake [25] on cassava depicted that excess moisture stress increased dry matter accumulation in rootstock, fibrous and storage roots, but decreased partitioning to stems and leaves. Drought stress reduced dry matter allocation to storage roots, but increased partitioning to rootstocks, fibrous roots and stems. The proportion of total dry matter partitioned to roots was higher while dry matter allocation to leaves was lower for the partial root zone drying treatment than in well-watered coffee plants [19].

\subsection{Dry Biomass Accumulation in Leaves}

The interaction of variety and irrigation level on leaves dry mater partitioning were highly significant different $(\mathrm{p}<0.001)$ for coffee seedling. Accordingly H-823/98 (40.1\%) allocated more proportion of dry biomass to leaves in all irrigation regimes. in similar way, the dry biomass accumulation proportion to leaves among three irrigation were significantly $(p<0.0001)$ varied. But, there were no difference in biomass accumulation proportion to leaves under both $80 \%$ ETc and $120 \%$ ETc of irrigations. Interestingly, at $40 \% \mathrm{ETc}$, the biomass accumulation proportion in leaves was about $24.2 \%$ and $22.8 \%$ lower than $120 \%$ and $80 \% \mathrm{ETc}$ treatments, respectively. Irrespective of genotypes, H-929 genotype had accumulated greater dry matter proportions to leaves under $80 \%$ ETc and followed by H-739 (44.6\%) under 120\% ETc., whereas, the lower dry biomass accumulation proportion to leaves were recorded from H-957/98 (26.1\%), H-981/98 (31.3\%), H-929/98 (31.1\%), H-739 (31.6\%) and H-674 (31.4\%) genotypes under $40 \%$ ETc. Among these, H-857/98 genotype had significantly reduced dry matter allocation proportion to leaves under limiting soil moisture, 40\% ETc when compared to other treatments. In general, the fraction of dry matter allocated to leaves increased from $26 \%$ at $40 \%$ ETc to $48 \%$ at $120 \%$ ETc., which demonstrated that as supply of moisture increase the leaf growth increased and vise-verse. This implies that the coffee seedling cope with limiting soil moisture by maintaining of lower dry biomass accumulation proportion to leaves, thereby, reduce evaporation and conserving existing moisture. Similar research has been investigated by Tesfaye [19] that the proportion of total dry matter partitioned to roots was higher and biomass allocation to leaves was lower for the partial root zone drying than in well-watered plants. 


\subsection{Dry Biomass Accumulation in Stem}

The dry biomass accumulation proportion in stems were significantly $(\mathrm{p}<0.001)$ affected due to irrigation and varieties Irrespective of genotypes highly significant $(\mathrm{p}<0.001)$ different was noted. H-674/98 (35.9\%) and H-823 (30.6\%) genotypes accumulated greater and lower dry biomass allocation proportion in stems respectively. The irrigation treatment had significantly $(\mathrm{p}<0.001)$ altered the biomass accumulation proportion in stems, consequently, 40\%ETc irrigation had accumulated higher biomass proportion in stems relatively. Whereas, the lower proportion of biomass accumulation in stem were recorded from $80 \%$ ETc $(32.9 \%)$ and $120 \%$ ETc $(32 \%)$, and there were no significances difference between $80 \%$ ETc and $120 \%$ ETc of irrigations.

Irrespective of interactions, the greater biomass accumulation proportion had recorded from, H-739/98 (38.3\%), H-857 /98 (37.1\%) and H-739 (36.4\%) under 40\% ETc and H-929 (39.2\%) under 120\%ETc. whereas, lower biomass accumulation proportion to stem observed in $\mathrm{H}$ 929/98 (27.8\%) and H-739 (29.7\%) under 80\%ETc. This indicated that under stress condition $(40 \% \mathrm{ETc})$ most coffee seedling accumulated higher dry biomass proportions to stems than leaves relatively, to reduce evaporating surface.

\subsection{Dry Biomass Accumulation to Roots}

There were significant $(\mathrm{p}<0.0001)$ dry biomass accumulation proportion differences in roots due to variety and irrigations. Regardless of genotypes, H-823 (29.3\%) and H-857 (29.6\%) genotypes had accumulated higher dry matter proportions in roots and lower accumulation in $\mathrm{H}$ $929(25.8 \%)$. There were highly significant $(\mathrm{p}<0.01)$ differences among irrigation treatments. Interestingly, under $40 \%$ ETc of irrigation dry biomass partition in roots were significantly increased by about $25.9 \%$ and $24.5 \%$ than $80 \%$ ETc and $120 \%$ ETc, respectively. In contrast, the variation in dry biomass accumulation proportion for root was not noticed under $80 \%$ and $120 \%$ ETc irrigation treatments. Moreover, the greater biomass allocation proportion to roots was observed in $\mathrm{H}-857 / 98$ (36.6\%) and H-981/98 (33.82\%) under 40\%ETc irrigation interactions and while the lower dry biomass partition to roots were recorded from H-929 (22.5\%) under 120\% ETc and H-674 (23\%), H-929 (23.8\%) and H-981/98 (24.1\%) under $80 \%$ ETc. Therefore, the growth and biomass allocation to different plant organ is more or less balanced under well watered plants $(80 \%$ and $120 \%$ ETc), which enhance carbon assimilation through improved photosynthetic capacity. Nearly all genotypes accumulated more biomass to roots as supplies of moisture become decreased. Whilst, for some genotypes, the fraction of biomass portioned to root become dropped under excess moisture supply condition. The investment made in the root organ at expense of shoot is to overcome limited moisture and extract more water from the deeper soil layer, if moisture is limited in soil layer within rooting depth. This finding agrees with Taye [20] who reported that higher root dry mass in drought- stressed than in well-irrigated seedlings. This response could suggest a drought-stress tolerance strategy investing more of the daily biomass production in the root system at the expense of the shoot system; enable the plants for searching moisture from deeper soil layer. Also similar works has been reported by Tesfaye [19], indicating that the proportion of total dry matter partitioned to roots was higher and biomass allocation to leaves was lower for soil moisture stressed treatment than in wellwatered plants.

Table 1. Effects of genotypes and different irrigation regimes on dry matter accumulation distribution to roots, stems and leaves.

\begin{tabular}{llll}
\hline Treatments & Stem $(\%)$ & Leaf $(\%)$ & Root $(\%)$ \\
\hline variety & $* *$ & $* *$ & $* *$ \\
H674 & $35.96 \mathrm{a}$ & $37.50 \mathrm{bc}$ & $26.53 \mathrm{bc}$ \\
H739 & $32.70 \mathrm{c}$ & $38.77 \mathrm{ab}$ & $28.50 \mathrm{ab}$ \\
H823 & $30.57 \mathrm{~d}$ & $40.19 \mathrm{a}$ & $29.29 \mathrm{a}$ \\
H857 & $33.87 \mathrm{bc}$ & $36.54 \mathrm{c}$ & $29.60 \mathrm{a}$ \\
H929 & $34.90 \mathrm{~b}$ & $39.20 \mathrm{ab}$ & $25.89 \mathrm{c}$ \\
H981 & $33.60 \mathrm{bc}$ & $37.99 \mathrm{bc}$ & $28.39 \mathrm{ab}$ \\
LSD @0.05 & 1.6 & 2.02 & 2.2 \\
CV $(\%)$ & 5.1 & 5.4 & 8.15 \\
Irrigation & $* * *$ & $* * *$ & $* *$ \\
$40 \%$ ETc & $35.70 \mathrm{ab}$ & $31.84 \mathrm{~b}$ & $32.37 \mathrm{a}$ \\
$80 \%$ ETc & $32.99 \mathrm{~b}$ & $41.27 \mathrm{a}$ & $25.70 \mathrm{~b}$ \\
$120 \% \mathrm{ETc}$ & $32.01 \mathrm{~b}$ & $41.99 \mathrm{a}$ & $25.99 \mathrm{~b}$ \\
LSD @ 0.05 & 1.17 & 1.4 & 1.5 \\
Variety X Irrigation & $* * *$ & $* * *$ & $* * *$ \\
\hline
\end{tabular}

Means followed by the same letters in column are not statistically different at $5 \%$ level for Least Significant Difference Test. *Significant at $\mathrm{p}<0.05$, $* *$ significant at $\mathrm{p}<0.01$ and $* * *$ significant at $\mathrm{p}<0$.

Table 2. Interaction effects of different irrigation regimes and genotypes on dry matter accumulation distribution to roots, stems and leaves.

\begin{tabular}{lllll}
\hline Variety & Irrigation Levels & Stem (\%) & Leaf (\%) & Root (\%) \\
\hline H674 & $40 \%$ ETc & $36.4 \mathrm{abc}$ & $33.45 \mathrm{f}$ & $30.12 \mathrm{~b}-\mathrm{d}$ \\
H674 & $80 \%$ ETc & $36.03 \mathrm{bc}$ & $40.92 \mathrm{~cd}$ & $23.05 \mathrm{gh}$ \\
H674 & $120 \%$ ETc & $35.40 \mathrm{c}$ & $38.14 \mathrm{de}$ & $26.44 \mathrm{~d}-\mathrm{g}$ \\
H739 & $40 \%$ ETc & $38.30 \mathrm{ab}$ & $31.64 \mathrm{f}$ & $30.00 \mathrm{~b}-\mathrm{d}$ \\
H739 & $80 \%$ ETc & $29.70 \mathrm{ef}$ & $40.10 \mathrm{cde}$ & $30.18 \mathrm{~b}-\mathrm{d}$ \\
H739 & $120 \%$ ETc & $30.14 \mathrm{ef}$ & $44.60 \mathrm{~b}$ & $25.29 \mathrm{e}-\mathrm{h}$ \\
H823 & $40 \%$ ETc & $30.35 \mathrm{ef}$ & $37.30 \mathrm{e}$ & $32.29 \mathrm{bc}$ \\
H823 & $80 \%$ ETc & $30.70 \mathrm{e}$ & $40.40 \mathrm{cde}$ & $28.83 \mathrm{c}-\mathrm{d}$ \\
H823 & $120 \%$ ETc & $30.40 \mathrm{ef}$ & $42.80 \mathrm{~cd}$ & $26.70 \mathrm{~d}-\mathrm{g}$ \\
H857 & $40 \%$ ETc & $37.12 \mathrm{abc}$ & $26.106 \mathrm{~g}$ & $36.66 \mathrm{a}$ \\
H857 & $80 \%$ ETc & $32.50 \mathrm{de}$ & $41.47 \mathrm{bcd}$ & $26.01 \mathrm{e}-\mathrm{h}$ \\
H857 & $120 \%$ ETc & $31.90 \mathrm{e}$ & $41.90 \mathrm{~cd}$ & $26.12 \mathrm{e}-\mathrm{h}$ \\
H929 & $40 \%$ ETc & $37.60 \mathrm{abc}$ & $31.10 \mathrm{f}$ & $31.29 \mathrm{bc}$ \\
H929 & $80 \%$ ETc & $27.89 \mathrm{f}$ & $48.31 \mathrm{a}$ & $23.81 \mathrm{f}-\mathrm{h}$ \\
H929 & $120 \%$ ETc & $39.17 \mathrm{a}$ & $38.23 \mathrm{de}$ & $22.58 \mathrm{~h}$ \\
H981 & $40 \%$ ETc & $34.82 \mathrm{~cd}$ & $31.36 \mathrm{f}$ & $33.82 \mathrm{ab}$ \\
H981 & $80 \%$ ETc & $35.15 \mathrm{~cd}$ & $40.76 \mathrm{~cd}$ & $24.10 \mathrm{f}-\mathrm{h}$ \\
H981 & $120 \%$ ETc & $30.873 \mathrm{e}$ & $41.87 \mathrm{~cd}$ & $27.25 \mathrm{~d}-\mathrm{f}$ \\
LSD @ 0.05 & & 2.8 & 3.34 & 3.8 \\
\hline
\end{tabular}

Means followed by the same letters in column are not statistically different at $5 \%$ level for Least Significant Difference Test. *Significant at $\mathrm{p}<0.05$, $* *$ significant at $\mathrm{p}<0.01$ and $* * *$ significant at $\mathrm{p}<0.001$. 


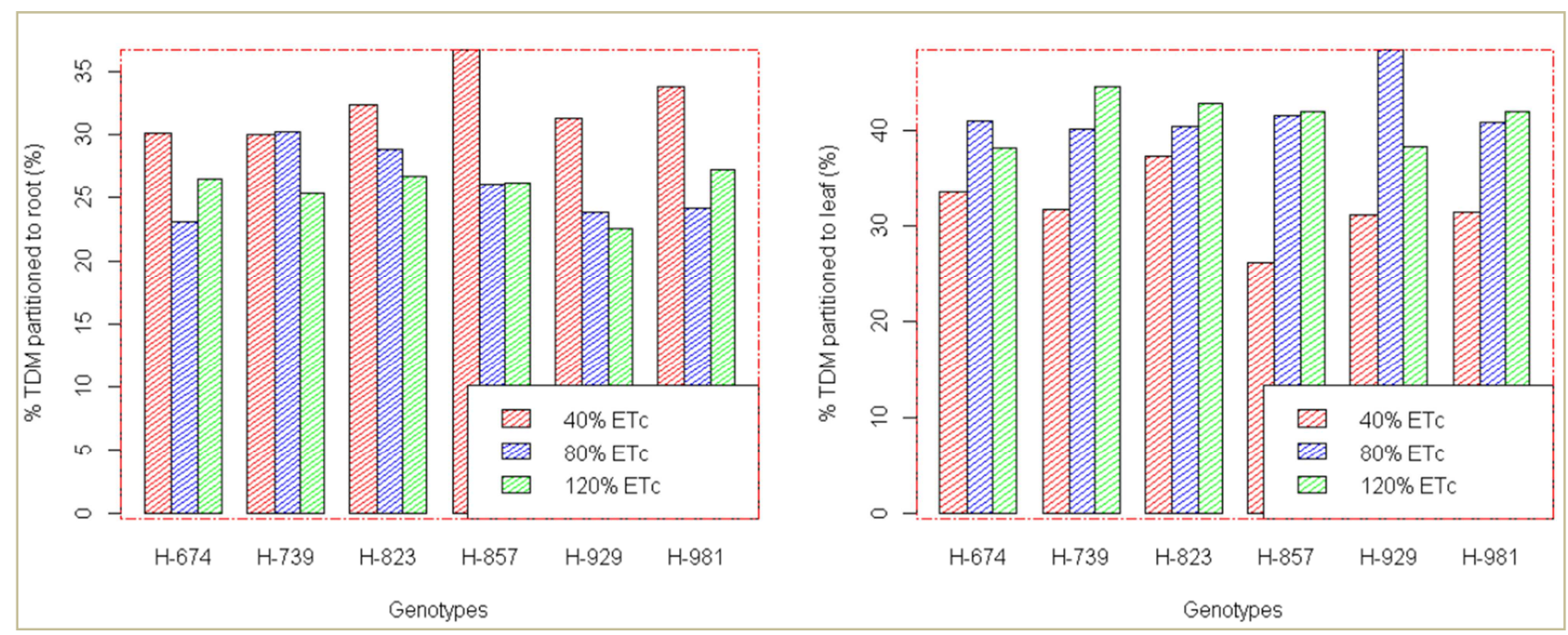

Figure 1. Fraction of biomass allocated to root and leaf.

\section{Conclusion}

From this experiment we concluded that the biomass production and allocation pattern varied due to deficit irrigation as well as genotypes or their combinations. Coffee root system compromised $37 \%$ of total plant under $40 \%$ ETc level, finally dropped to $23 \%$ under 120 ETc level; suggesting that such greater variation is possibly as consequence of watering amount. In detail, in drought condition, the coffee seedling accumulates greater dry matter to roots at the expense of shoots, then able to extract more water from deeper soil. In contrast, in fully irrigated coffee, they tend to accumulate more dry-mater to shoots than roots to enhance photosynthetic capacity. Therefore, this finding provides important information which helps to evaluate and characterize growth response of coffee genotypes to induced deficit irrigation. The result also helps to identify drought tolerant genotypes for drought prone locations like Hararhe area under changing climatic condition. However, to understand the adaptation mechanism among coffee genotypes, it requires a detail study at field experiment under contrasting environmental conditions.

\section{References}

[1] ICO. 2010. International Coffee Organization. Annual Review. http://www.ico.org/

[2] Tesfaye, S. G, Ismail, M. R., and Mahmood, M., 2008. Effects of deficit irrigation and partial rootzone drying on growth, dry matter partitioning and water use efficiency in young coffee (Coffeaarabica L.) plants. Journal of Food, Agriculture \& Environment Vol. 6 (3 \& 4): 312-317. 2008.

[3] Araujo WL, Dias PC, Moraes GA, Celin EF, Cunha RL, Barros RS, DaMatta FM (2008) Limitations to photosynthesis in coffee leaves from different canopy positions. Plant Physiol Biochem 46: 884-89.
[4] DaMatta FM, Ronchi CP, Maestri M, Barros RS (2007) Ecophysiology of coffee growth and production. Braz J Plant Physiol 19: 485-510.

[5] Bruno, I. P., Reichardt, K., Bortolotto, R. P., Pinto, V. M., Bacchi, O. O. S., Dourado-Neto, D. and Unkovich, M. J., 2015. Nitrogen balance and fertigation use efficiency in a field coffee crop. Journal of Plant Nutrition, 38 (13), pp. 2055-2076.

[6] Harmand J-M, Ávila H, Dambrine E, Skiba U, de Miguel S, Renderos RV, Oliver R, Jiménez F, Beer J (2007) Nitrogen dynamics and soil nitrate retention in a Coffea arabicaEucalyptus deglupta agroforestry system in Southern Costa Rica. Biogeochem 85: 125-139.

[7] Jaramillo-Botero C, Santos RHS, Martinez HEP, Cecon PR, Fardin MP (2010) Production and vegetative growth of coffee trees under fertilization and shade levels. Scientia Agricola 67: 639-645.

[8] Fahl J, Carelli M, Vega J, Magalhães A (1994) Nitrogen and irradiance levels affecting net photosynthesis and growth of young coffee plants (Coffea arabica L.). J Hort Sci 69: 161170 .

[9] Siles P, Harmand J-M, Vaast P (2010) Effects of Inga densiflora on the microclimate of coffee (Coffea arabica L.) and overall biomass under optimal growing conditions in Costa Rica. Agroforestry Systems 78: 269-286.

[10] Perfecto, I., Rice, R. A., Greenberg, R. and Van der Voort, M. E., 1996. Shade coffee: a disappearing refuge for biodiversity: shade coffee plantations can contain as much biodiversity as forest habitats. BioScience, 46 (8), pp. 598-608.

[11] DaMatta, F. M. and Ramalho, J. D. C., 2006. Impacts of drought and temperature stress on coffee physiology and production: a review. Brazilian journal of plant physiology, 18 (1), pp. 55-81.

[12] DaMatta, F. M., 2004. Exploring drought tolerance in coffee: a physiological approach with some insights for plant breeding. Brazilian journal of plant physiology, 16 (1), pp. 1-6.

[13] Brouwer R (1962) Nutritive influences on the distribution of dry matter in the plant. Neth J Agric Sci 10: 399-408. 
[14] Lambers H (1983) The functional equilibrium, nibbling on the edges of a paradigm. Neth J Agric Sci 31: 305-311.

[15] Poorter H, Remkes C (1990) Leaf area ratio and net assimilation rate of 24 wild species differing in relative growth rate. Oecologia 83: 553-55.

[16] CHB. 1987. Coffee Hand Book (CHB). Coffee Growers Association, Harare, Zimbabwe, Canon Press (Pvt) Ltd.

[17] Setter, T. L. 1992. Assimilate allocation in response to water deficit stress. International Crop Science. pp. 733-735. Crop Science of America, Inc., Madson, Wisconsin, USA.

[18] Chaves, R. M., Ten-Caten, A., Pinheiro, H. A., Ribeiro, A. and Damatta, F. M. (2008) Seasonal changes in photopro- tective mechanisms of leaves from shaded and unshaded field-grown coffee (Coffea arabica L.) trees. Trees, 22, 351-361. Doi: 10.1007/s00468-007-0190-7.

[19] Tesfaye, S. G., 2008. Effects of deficit irrigation and partial rootzone drying on growth, dry matter partitioning and water use efficiency in young coffee (Coffea arabica L.) plants.
[20] Taye, K. 2012. Biomass production and distribution in seedlings of Coffea arabica genotypes under contrasting nursery environments in southwestern Ethiopia. Agricultural Sciences, 3 (06), p. 835.

[21] James S. McDonald, Tom Ericsson and Carl-Magnus Larsson. 1996 Plant nutrition, dry matter gain and partitioning at the whole-plant level. Journal of Experimental Botany. 47: 12451253.

[22] Ericsson T. 1995. Growth and shootroot ratio of seedlings in relation to nutrient availability. Plant and Soil 168/169: 205-14.

[23] Mendiburu, F. and deMendiburu, M. F., 2019. Package 'agricolae'. R Package, Version, pp. 1-2.

[24] Team, R. C., 2013. R: A language and environment for statistical computing.

[25] Lahai, M. and Ekanayake, I., 2009. Accumulation and distribution of dry matter in relation to root yield of cassava under a fluctuating water table in inland valley ecology. African Journal of Biotechnology Vol. 8 (19), pp. 4895-4905. 